\title{
Autonomous learning of college English based on network and
}

\section{multimedia}

\author{
Zhao Hui Min ${ }^{1, \text { a }}$ \\ ${ }^{1}$ Bohai university, Jinzhou, 121013 China \\ ahmzhao2008@163.com
}

Keywords: College English education, Autonomous learning, Network

\begin{abstract}
Currently, college English education still stays in the traditional mode. Students have very poor autonomous learning ability and can not actively acquire knowledge. It becomes the crucial problem to cultivate the autonomous learning ability and improve the English comprehensive ability. The author puts forward the specific strategies of autonomous learning based on the network multimedia technology. The purpose of these strategies aims to improve the autonomous learning ability for students as well as the efficiency of class teaching for teacher.
\end{abstract}

\section{Introduction}

Currently, the obsolete teaching mode has seriously impeded the development of college English education. In 2004, education ministry of China put forward the goal of cultivating students' comprehensive application ability, especially listening and speaking ability. Essentially, the mode of college English autonomous and cooperative learning stresses the learning initiative and enthusiasm of students and it aims to improve the autonomous learning ability of students, including lifelong learning ability, creative ability, skills of social communication as well as the spirit of cooperation. At the same time, it pursues the combination of foreign language learning and affective education, which promotes the full development of students. Network and multimedia technology provides hypertext structure and large amount of information as well as many intelligent learning platforms. Learning via network and multimedia is not limited by time and space. Meanwhile, it can provide the ideal conditions and space for students, so it can satisfy the different learning requirement of college students. In this environment, the learning style of students inevitably changes, i.e., the transition from mono-textbook learning to multimedia learning, the change from traditional class learning to the autonomous learning[1]. The change of learning mode has great influence on the acquisition of knowledge and information for students. Therefore, it is important to explore the new autonomous learning mode for the college English teaching and learning. In this article, we explore the concrete strategies for autonomous learning and investigate how to carry out the autonomous learning via network and multimedia. We propose a new learning mode that can greatly optimize the autonomous learning via network.

\section{Constructivism and autonomous learning}

The concept of autonomous learning was formed in 1960s. It is based on the theory of constructivism, which holds the belief that learners construct new knowledge on the basis of their 
previous knowledge and experience. Constructing new knowledge is the process with initiative and creativity. The teaching mode of constructivism emphasizes that learning should be student-centered. Students are the main body of learning and they recognize and process information and knowledge by exploring and discovering. Teacher plays the role of instructor, supervisor, organizer and facilitator in the learning process of students. Constructivism stresses the subject position of students and meanwhile does not neglect the guiding role of teacher. English is the language course with much practice. Therefore, it is much better to learn English in practice rather than in class. In language learning, students play the crucial role and determine the learning process. Holec once pointed that the goal of foreign language learning is not only to help students acquiring language knowledge and communication skills[2], but also to help them acquire autonomous learning ability, that is, students should learn the skills of 'how to learn autonomously'. English teacher should help students exploit the initiative, accelerate the reorganization and reconstruction of new knowledge, construct the student-centered teaching process. Students should participate in the learning process actively and meanwhile the teacher guides the students effectively and purposely. Therefore, autonomous learning ability takes an important part in English learning. English education not only helps the students acquire the knowledge, but also cultivates the autonomous learning ability.

\section{Strategies of autonomous learning}

(I) Preparing stage of autonomous learning. In this stage, students are asked to learn via network and acquire knowledge autonomously.

(i) Make the learning plans. Teacher asks the students to make their learning plans according to their learning abilities and the teaching goals. The learning goal should be concrete and feasible. In time, it should include the immediate-term, medium-term and long-term plans and contain listening, speaking, reading, writing, translation and other skill training. Teacher should fully know the personality and individual differences of students. Further, teacher should combine the autonomous learning with the class teaching and make the students aware of the task and goals of each class, and make sure that the students acquire the knowledge in the training process.

(ii)Utilize non-intellectual factors for students. Teacher should encourage students to communicate from the beginning and make the students aware of the ultimate goal of communication with others, and help students to carry out any activities that can freely use English language. In this process, students should learn not only the knowledge, but also the learning method. And the autonomous learning ability should be developed in the process. Most importantly, non-intelligent factors, e.g., the will and perseverance, should be cultivated in the process.

(iii)Learn before class through group interaction. Teacher should first divide the whole class into 3 to 4 groups. Students in group learn knowledge by cooperating with others and supervising each other. Each student undertakes his own learning task designed by the group. Dividing the learning group can make the students aware of their responsibility and promote the communication between the students, and strengthen the cooperative learning and interpersonal communication. Then teacher dispatch the related topics and preview materials to the students via network. Students can search the background information and sort out the need information via network. They can learn the new words and phrases in the articles, which promotes the understanding on the structure and content of articles. Students discuss the topics, provided by the students, in group and present their own opinions and views. In this way, students can understand and grasp the contents before class. And most importantly, it can stimulate the learning motivation of students. 
(II) Implementation of autonomous learning. The key point is to use the network multimedia and carry out class teaching on the basis of preview.

(i) Students should play the leading role in class teaching. The traditional teaching mode was overturned under the environment of network multimedia. Teacher does not dominate the learning activities and the classroom now becomes the stage to practice English for students. Give the class time to students and make them become the initiator of learning. Establish and strengthen the awareness of autonomous learning for students.

(ii) Use the network multimedia to carry out group teaching. Teacher use the multimedia equipments to play the relevant content to the students and explain to the students if necessary. Question and group discussion are the main teaching form for the textbook content. After group discussion, the representatives of each group should give out and explain the discussion results to the whole class. After the presentation of the representatives, students ask their questions by combing their results of group discussion, and the exchange and discussion between groups can be carried out. In the above process, all the class students can utilize the equipment of multimedia to learn and discuss. In the teaching process, teacher should stimulate the enthusiasm of students to participate in the discussion and cooperation. The teaching activity should be carried out via task-based teaching mode, which can effectively inspire the thinking ability of students. Moreover, teacher should encourage the students to participate in the discussion and make each student to devote to the learning activity[3].

(iii) Evaluate the group discussion and presentation. After the discussion and presentation of group, teacher should evaluate the performance of each group, and comment on the situation of preparation and presentation and participation of each group. At the same time, teacher should summarize the related issues and explain some of them to the students. This can help the students understand and grasp the crucial part of issues.

(III) Consolidating stage with practicing, summarizing and inducting via network multimedia. After the class teaching, teacher should post the exercises and the related teaching courseware to the network. Students download the materials and refer to them for autonomous learning. The courseware posted by the teacher is mainly the hints of exercises, e.g., the principles of listening training, the reading skills for reading comprehension, the related vocabulary of translation, phrases and expressions, the background knowledge of writing topics, and word formation and collocation. The posted courseware should not be made into the answer form; otherwise the students may depend on these results and do not think and solve the question by themselves. The main content of courseware should be the hints for questions and it promotes the students to analyze and think the questions [4]. The main purpose is to cultivate the ability of solving the problems independently. Teacher should analyze and comment the exercises at the beginning of new class, and answer the questions asked by the students. In this way, students can learn to summarize through exercises and English learning can be more effective and targeted.

(IV) Evaluation of autonomous learning. An open evaluation system should be built via network and multimedia. The evaluation system includes self-evaluation, peer-evaluation and teacher-evaluation [5]. Each student can enter the evaluation system and get his own evaluating information. The overall evaluation system can effectively regulate and guide learning of students. In evaluation process, students find their participation and efforts recognized by the teacher and other students. This can effectively stimulate the enthusiasm of students and promote their learning. Self-evaluation means that students evaluate their own situations of learning progress, participation degree and achievement. Self-assessment is a manifestation of autonomous learning ability and it should be encouraged by teacher. When students assess their own learning, they can find the 
problems in learning and hence adjust to the situation and make an effort to learn. Peer-evaluation refers to the evaluation made by the students on the learning progress, participation and contribution. Peer-evaluation can make students aware of the progress of each other and establish the position and contribution of individual in the group learning. Teacher-evaluation is a comprehensive evaluation, including learning motivation, interest, goals, plans and implementation level. The evaluation systems complement each other and constitute an organic evaluating system.

\section{Conclusions}

We explore the concrete strategies that cultivate the autonomous learning ability of students via network and multimedia. These strategies can help the students utilize the network platform and internet resource to maximum effort. Our strategies can help the students collect, discover, create and display the resource of learning and effectively mobilize the learning initiative and enthusiasm of students.

\section{Acknowledgements}

This work is supported by Social Science Foundation of Liaoning Province (No. L15DWW005) and Bohai University Teaching Reform Project (No.BDJG15QNB002).

\section{References}

[1] D. Gardner, Self-assessment for autonous language learners, Links \& Letters 7: 49-60 (2000)

[2] H. Holec, Autonomy and Foreign Language Learning [M] . Oxford: Pergamon Press, 1981.

[3] A. Schale, A. Szabo, Learner Autonomy: A Guide to Developing Learner Responsibility. London: Cambridge University Press. 2000

[4]V. Stevens, A study of student attitude toward CALL in a self-access student resource center, System 19(2): 289-299 (1991).

[5]L.A.J. Stefani, “Peer, self, and tutor assessment: Relative reliabilities”. Studies in Higher Education 19: 69-75 (1998). 